\title{
EL GAMBRINUS HALLE (1894), UN CAFÉ-CERVECERÍA A LA ÚLTIMA MODA EN EL CENTRO DE FLORENCIA
}

\section{THE GAMBRINUS HALLE (1894), A FASHIONABLE CAFÉ-BEER HOUSE IN THE CENTRE OF FLORENCE}

\author{
Mónica Vázquez Astorga ${ }^{1}$ \\ Universidad de Zaragoza
}

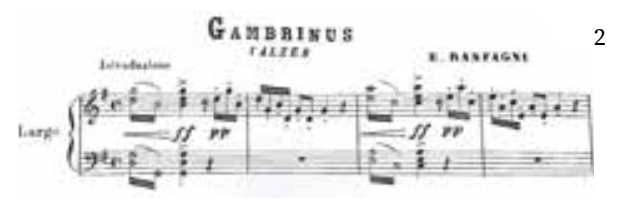

\section{RESUMEN}

Este trabajo se centra en el estudio del Gambrinus Halle de Florencia (Italia), que fue inaugurado el 29 de noviembre de 1894. Los críticos de la época acogieron con grandes elogios su apertura y destacaron la elegancia de su instalación y sus amplias dimensiones conseguidas gracias al empleo de nuevos materiales y técnicas de construcción. De hecho, fue uno de los cafés-cervecerías más grandes de Europa. Fue fundado por Spirito Giamello en la recién creada piazza Vittorio Emanuele II (actual piazza della Repubblica), que se convirtió en el «salón urbano» preferido para la sociedad burguesa florentina. Este establecimiento, al igual que otros emplazados en este espacio, fue importante como lugar de encuentro y reunión de relevantes personalidades, principalmente de la actualidad artística. Estuvo en funcionamiento hasta comienzos de la década de los veinte de la pasada centuria, momento en el que sus locales fueron destinados a sala cinematográfica y que ahora acogen un Hard Rock café. Con este texto se pretende contribuir al conocimiento y valoración de este centro que fue instituido para rendir culto al legendario Gambrinus.

Palabras clave: Gambrinus Halle/café-cervecería/Florencia/cafés históricos/espacios de sociabilidad/ lugares de reunión y de tertulias.

\section{ABSTRACT}

This work focuses on the study of the Gambrinus Halle, which opened in Florence, Italy, on 29 November 1894. The critics of the time praised the opening and emphasised the elegance and spaciousness of the premises, resulting from the use of new building materials and techniques. In fact, the establishment was one of the biggest cafés-beer houses in Europe. The Gambrinus Halle was founded by Spirito Giamello in the newly built piazza Vittorio Emanuele II (nowadays piazza della Repubblica), which became the favourite "urban hall" of the middle-class society of Florence. As other establishments located in the area, it was a major meeting point for relevant figures, specially artists. It remained in business until the 1920s, when its halls were turned into a cinema, and it now houses a Hard Rock café. This work aims at making this establishment, founded to praise the legendary Gambrinus, better known and appreciated.

Keywords: Gambrinus Halle/café-beer house/Florence/historic cafés/spaces for sociability/ spaces for reunion and circles.

1 Profesora Titular del Departamento de Historia del Arte de la Universidad de Zaragoza. Correo electrónico: mvazquez@unizar.es. ORCID iD: http://orcid.org/0000-0002-7849-8772.

La presente investigación se enmarca en el Proyecto de Investigación I+D+i Distritos culturales de Museos, Galerías, Establecimientos y Paisajes urbanos patrimoniales, financiado por la Secretaria de Estado de I+D+i del Ministerio de Ciencia, Innovación y Universidades (código PGC2018-094351-B-C41) (MCIU/FEDER).

En el año de 2015 se publicó un libro sobre los cafés históricos de Florencia (Vázquez, 2015), en el que se dedicó un apartado al café-cervecería Gambrinus. En este artículo se realizan nuevas aportaciones que contribuyen a completar su estudio histórico-artístico y a valorar su papel como espacio para la práctica de la sociabilidad pública.

2 Esta imagen recoge los primeros compases de la partitura que fue dedicada por el maestro Enrico Ranfagni a Spirito Giamello, propietario del Gambinus, con motivo de su inauguración. La adquisición de esta partitura ha sido esencial para tener más noticias acerca de la decoración de este café-cervecería, puesto que aparece ilustrada con el cuadro que Alberto Micheli realizó para ornar su interior. 


\section{INTRODUCCIÓN}

Florencia es un referente para el estudio de los cafés históricos europeos fundados entre la segunda mitad del siglo XIX y la primera de la siguiente centuria ${ }^{3}$, dado que en esta ciudad desempeñaron un papel importante como lugares de encuentro social y difusión de ideas, sobre todo en el campo artístico, literario y político. A este respecto, cabe recordar el acreditado Michelangelo (instalado en 1848, via Larga -actual via Camillo Cavour-, núm. 21), que puede considerarse como el primer café literario-artístico de esta urbe. Contaba con dos salas, de las cuales fue célebre la segunda de ellas porque acogió, hacia mediados de los cincuenta, un cenáculo llamado la chiesuola dell'Arno, que estuvo presidido por el crítico Adriano Cecioni y el pintor Telemaco Signorini y donde se dio vida al movimiento de los macchiaioli, quienes abrieron el camino hacia la renovación pictórica en Italia (Cecioni, 1905: 287).

No obstante, los cafés que dieron y siguen dando renombre a la ciudad del Arno se concentran en la piazza della Repubblica (anteriormente denominada piazza Vittorio Emanuele II) y abrieron sus puertas entre la última década del siglo XIX y la segunda del XX, en el momento de mayor desarrollo de estos establecimientos ${ }^{4}$, para satisfacer la demanda de ocio y de asueto por parte de la burguesía florentina. Uno de los últimos en instalarse en este espacio urbano fue el café-cervecería Gambrinus en 1894, a cuyo estudio dedicamos este trabajo, puesto que reúne las características del modelo de café de la época y especialmente porque, entre los existentes en Europa con igual denominación, destacaba por sus vastas dimensiones (conseguidas gracias al empleo de nuevas técnicas y materiales de construcción), comodidad y fastuosidad. De hecho, era conocido como Gambrinus Halle -haciendo referencia así al término germánico halle que significa espacio amplio y cubierto- y era fiel testimonio de la Belle Époque.

Los cafés surgieron en la Europa del siglo XVIII cuando las relaciones sociales experimentaron cambios notables, de acuerdo con las transformaciones derivadas del reformismo ilustrado. De este modo, y como constata María de los Ángeles Pérez, el consumo de esa bebida exótica generaría y daría nombre a estos locales especializados, que fueron resultado de los progresos sociales y umbral del futuro desarrollo de nuestra sociedad (Pérez, 2001: 12).

La aparición de estos establecimientos públicos de sociabilidad ${ }^{5}$ enlaza, como señala Francisco Villacorta, con el nacimiento coetáneo en Europa de una serie de instituciones (salones, clubs políticos, sociedades patrióticas, ateneos, círculos masónicos o centros artísticos) vinculadas con la configuración del espacio liberal y burgués que organiza la competencia ideológica en las nuevas tareas del gobierno político y en el reconocimiento y promoción de los nuevos gustos culturales (Villacorta, 2003: 416). Cada una de estas entidades tenía sus propios fines aunque algunas de sus funciones se entrecruzaban como podían ser la promoción cultural y la discusión sobre temas de actualidad.

Para emprender este estudio, aludimos, en primer lugar, al proyecto de reordenación del centro histórico de Florencia que se materializó en la conformación de la piazza Vittorio Emanuele II, en la que se congregaron, en la década de los noventa del siglo XIX y comienzos de la siguiente centuria, elegantes cafés -así como restaurantes y hoteles- que fueron testimonio de la imagen renovada que quería ofrecer la antigua capital del reino de Italia. Uno de ellos fue el Gambrinus, que está considerado como unos de los más grandes de Europa; y, en segundo lugar, trazamos la historia de este establecimiento dedicado al mítico «rey de la cerveza» y valoramos su función y repercusión como espacio de sociabilidad pública.

3 Sobre este tema de los cafés europeos existentes en el último cuarto del siglo XIX véase, entre otras publicaciones: (Vázquez, 2015: 23-37).

4 Antonio Bonet Correa señala que el período comprendido entre el último tercio del siglo XIX y los primeros años del siglo XX se corresponde con la Edad de Oro de los cafés en Europa. Estos locales destacaban por su amplitud, comodidad y lujo, y tenían como principal referente los parisinos que se habían convertido en modelo a imitar (Bonet, 2012: 38).

5 Los cafés han sido estudiados a través del concepto de sociabilidad definido por el hispanista Jean-Louis Guereña como la aptitud de los hombres para relacionarse en colectivos más o menos estables, más o menos numerosos, y a las formas, ámbitos y manifestaciones de vida colectiva que se estructuran con este objetivo (Guereña, 2003: 413). 


\section{LA PIAZZA VITTORIO EMANUELE II: UNA NUEVA IMAGEN PARA UNA CIUDAD BURGUESA}

En 1882 se puso en marcha el dilatado y polémico plan de reordenación del centro histórico de Florencia (en torno a la piazza del Mercato Vecchio) denominado Risanamento ${ }^{6}$. Su fundamento era «sanearlo y mejorarlo» ${ }^{7}$ y transformarlo en una nueva plaza (que llevaría el nombre de Vittorio Emanuele II) que reflejara la prestancia de la sociedad burguesa decimonónica; una sociedad de buen tono que dictaba las normas de comportamiento a través de la moda y el refinamiento (Cruz, 2014: 50). Esta grandiosa actuación urbanística es consecuencia de cuando Florencia se convirtió en la capital del reino de Italia, entre 1865 y 1870 (fecha en la que fue trasladada a Roma), estado que requirió nuevas exigencias económicas, sociales y urbanas ${ }^{8}$.

Este proyecto conllevó lamentablemente la desaparición del ghetto ebraico ${ }^{9}$, de la piazza del Mercato Vecchio (FIGURA 1) ${ }^{10}$ y de la Loggia del Pesce (donde se colocaban los vendedores de pescado en esa plaza) ${ }^{11}$, es decir, de la parte más central y antigua de la ciudad (que fue el primer núcleo de la Florencia romana y después de la medieval), con la especulación, expropiación y demolición de sus prestigiosos inmuebles y pintorescos comercios (Detti, 1977: 83-92). Esta intervención especulativa eliminó los espacios estrechos y las antiguas calles para dar paso a nuevas y rectilíneas vías y a la moderna y uniforme plaza ideada en homenaje al monarca Vittorio Emanuele II, artífice de la unificación de Italia.

A lo largo del año de 1889 se seguía trabajando en la urbanización de la Nuova Piazza del Centro, que fue denominada de Vittorio Emanuele II (en la actualidad piazza della Repubblica) (FIGURA 2) $^{12}$, y, en enero del siguiente año, se dispuso en su centro el basamento de la estatua ecuestre en bronce de este monarca, que fue realizada por el escultor florentino Emilio Zocchi y que desde 1932 se halla en la piazza Vittorio Veneto, a la entrada del parque delle Cascine $^{13}$. Esta obra marcó el nacimiento de la nueva zona burguesa y la desaparición del corazón popular de Florencia.

6 En los acuerdos municipales tomados entre marzo y abril de 1882 se decidió, entre otras cuestiones, que la zona comprendida dentro de la reordenación del centro histórico tuviera los siguientes límites: $1^{\circ}$ via Calzaiuoli; $2^{\circ}$ via Porta Rossa; $3^{\circ}$ via dei Tornabuoni, piazza San Gaetano e via Rondinelli; $4^{\circ}$ via Cerretani; y $5^{\circ}$ piazza San Giovanni. Además, se propuso la conformación de cuatro ejes principales (que comunicarían el centro con otras partes de la ciudad): via degli Strozzi e via degli Speziali, con su prolongación hasta via Calzaiuoli; via Calimala, dei Succhielinaj e dell'Arcivescovado (actual via Roma), con la prolongación hasta canto alla Paglia; via delle Nave, del Refenero, etc., con la prosecución hasta via Tornabuoni; via Pellicceria y dei Naccajoli (hoy via dei Brunelleschi), con su prolongación; y via del Beccuto, degli Agli y dei Vecchietti, con su prosecución hasta via Porta Rossa (La Nazione, 24 de abril de 1882: 3). Este proyecto (piano regolatore per il riordinamento del centro) fue formulado por el ingeniero municipal Edoardo Rimediotti con fecha de 10 de julio de 1883. Su aprobación definitiva tuvo lugar mediante Real Decreto de 8 de marzo de 1888. En la propuesta inicial se fueron introduciendo modificaciones, entre las cuales, se hallaban las siguientes: trasladar el eje de la piazza del Mercato Vecchio haciéndole corresponder con el de via degli Speziali; suprimir los pórticos en tres lados de la plaza nueva; construir un pórtico cubierto en el lado Este de la via Pellicceria; y prolongar algunas calles como la via degli Speziali hasta via Strozzi. Archivio Storico del Comune di Firenze [en adelante ASCFI], Comune di Firenze, Filza A 5. Centro di Firenze. Carteggio n. 83, 1881 1899, CF 7165; (La Nazione, 15 de junio de 1883: 1-2); (La Nazione, 30 de diciembre de 1886: 3); y (La Nazione, 5 de mayo de 1889: 2).

7 Giovanni Fanelli señala que la zona del antiguo mercado, debido a sus precarias condiciones higiénicas, había constituido uno de los focos de la violenta epidemia de cólera que afectó a Florencia en 1835 (Fanelli, 2002: 447).

8 Sobre estas transformaciones acometidas en este período véanse, entre otras publicaciones: (Poggi, 1993) y (Romby, 2002: 48-56).

9 En 1571, Cosme I de Médici encargó al arquitecto florentino Bernardo Buontalenti adaptar un cuadrilátero de calles, ubicadas en el lado septentrional de la piazza del Mercato Vecchio, para residencia de la comunidad judía. Esta área, delimitada por una muralla, recibió el nombre de ghetto. En esta misma época fue construida la Loggia del Pesce. Los habitantes del gueto tuvieron de plazo hasta mayo de 1885 para su abandono, teniendo que buscar un nuevo alojamiento. En junio de ese año se cerró definitivamente. Un nuevo barrio judío se conformó en la zona denominada della Mattonaia (al norte de la via dei Pilastri) (La Nazione, 24 de abril de 1885: 3) y (La Nazione, 10 de junio de 1885: 3).

10 A la piazza del Mercato Vecchio, destinada a la venta diaria de comestibles, se accedía desde las siguientes vías: di Calimala, degli Speziali, delle Ceste, dei Succhiellinai, dei Rigattieri, dei Ferravecchi y di Pellicceria. En ella estaba emplazada la columna de la Abundancia (en el punto sudeste de la plaza), que fue desmontada durante la ejecución de los trabajos. En la actualidad, se encuentra en la piazza della Repubblica, en el mismo lugar donde estuvo en origen. Con la demolición del Mercato Vecchio se hizo necesario edificar nuevos mercados municipales como el de San Ambrogio (1873) y el central de San Lorenzo (inaugurado en 1874, cuyo proyecto fue redactado por el arquitecto Giuseppe Mengoni, autor de la famosa Galleria Vittorio Emanuele II de Milán, construida entre 1865 y 1877).

11 En la actualidad, la antigua Loggia del Pesce se halla ubicada en la populosa piazza dei Ciompi, en las proximidades de la piazza di Santa Croce.

12 Esta figura pertenece a ASCFI, Fondo disegni, Piazza Vittorio Emanuele, A.M.C.F.E. car. 058/039.

13 ASCFI, Comune di Firenze, Filza III. Inaugurazione del monumento a Vittorio Emanuele II Re d'Italia, 1890, fasc. 1, CF 4998; y (La Nazione, 14 de julio de 1889: 2). 


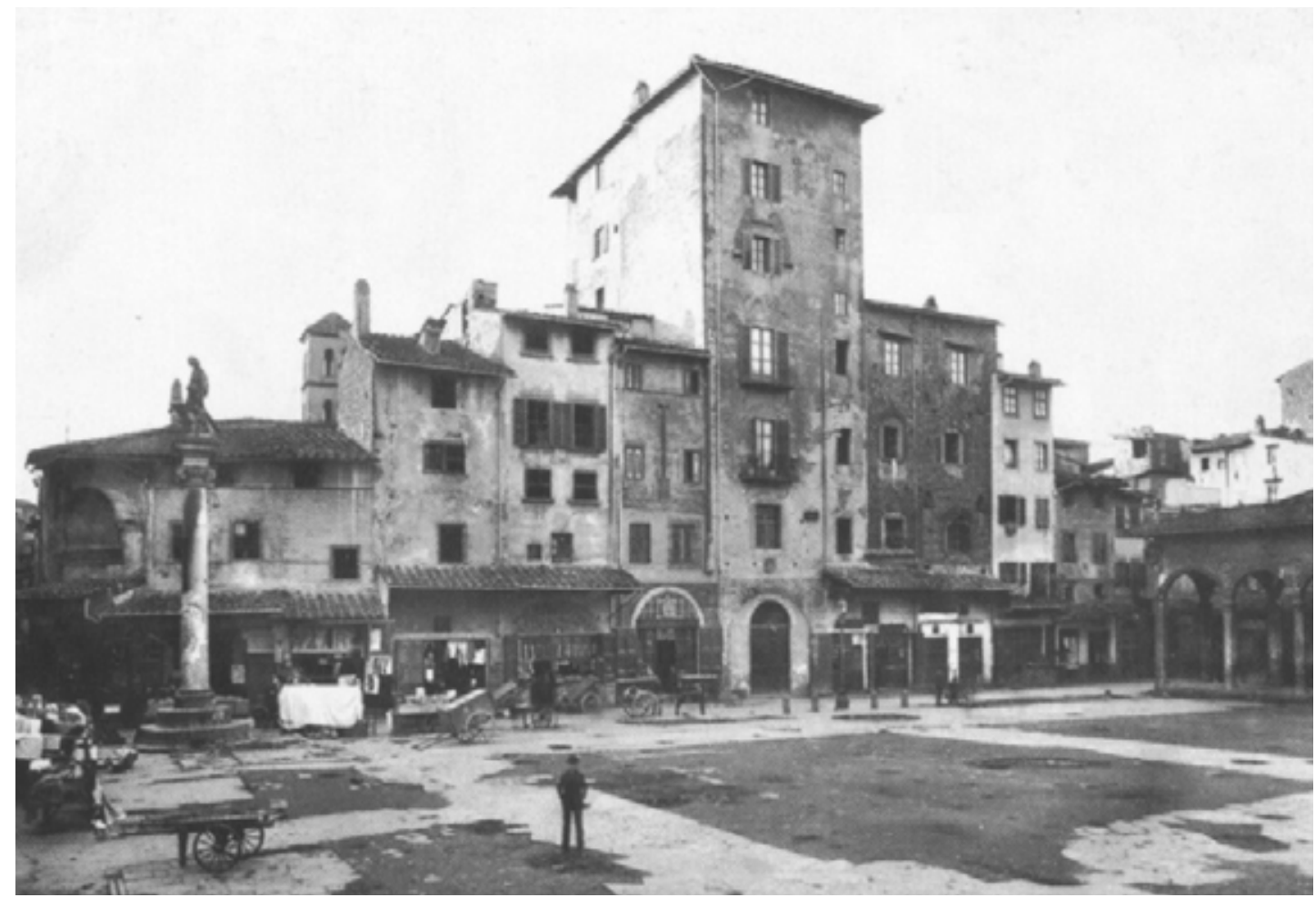

FIGURA 1. Aspecto parcial de la piazza del Mercato Vecchio con la columna de la Abundancia y la Loggia del Pesce. Hacia 1889. ASCFI

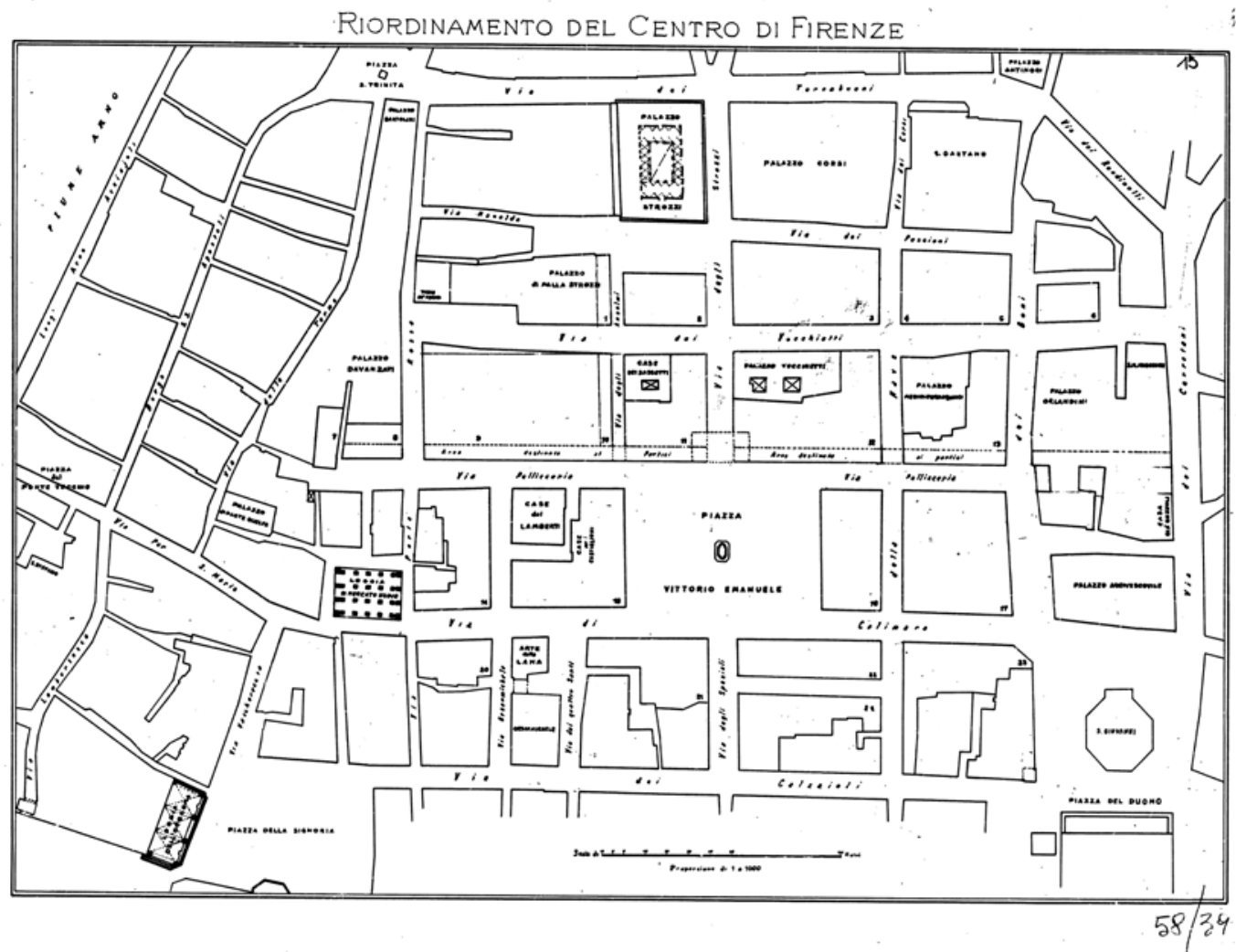

FIGURA 2. Proyecto de reordenación del centro de Florencia con la piazza Vittorio Emanuele II. ASCFI

En marzo de 1890 finalizaron los trabajos de demolición en la plaza, aunque continuaron en otros puntos para conseguir la reordenación interna programada (La Nazione, 3 de marzo de 1890: 3). El 20 de septiembre de ese año, con motivo del veinte aniversario de la toma de Porta Pia, tuvo lugar la solemne inauguración del monumento al monarca Vittorio Emanuele II, en presencia de sus sucesores Umberto I y Margherita di Savoia (La Nazione, 17 de septiembre de 1890: 2). 
Una vez urbanizada la piazza Vittorio Emanuele II se procedió a la construcción de edificios en sus lados, que constan de planta baja, mezzanino y tres más en altura, siguiendo así un criterio uniforme y homogéneo (FIGURA 3). En cuanto a su estilo, se recurrió al lenguaje historicista preeminente en la época, inspirado en la arquitectura renacentista propia de esta ciudad. En este sentido, hay que decir que en 1889 se había nombrado una comisión (integrada por los renombrados arquitectos Luigi Del Moro ${ }^{14}$, Giacomo Roster ${ }^{15}$ y G. Mariani) para examinar los proyectos de los inmuebles que debían erigirse en este espacio urbano, con el fin de que cumpliesen las ordenanzas municipales y que atendiesen tanto en planta como en alzado al decoro constructivo. Sus fachadas tenían que presentar una buena disposición de líneas y tener presente la tradición toscana ${ }^{16}$.

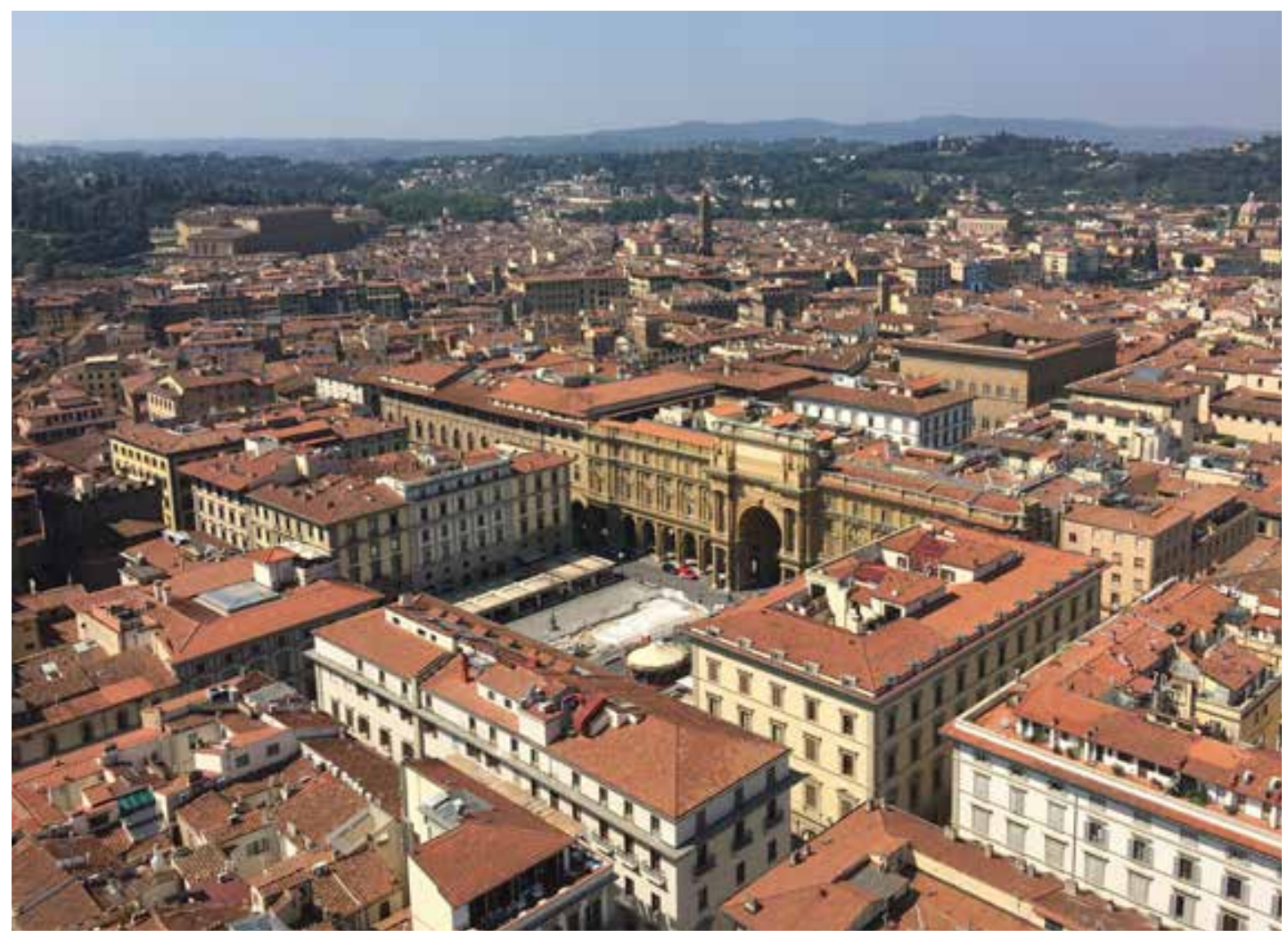

FIGURA 3. Vista parcial del centro de Florencia con la piazza della Repubblica. 2018. Autora

En 1892 estaba en ejecución el edificio promovido por los hermanos Ottavio y Enrico Levi en el lado Norte de la plaza ${ }^{17}$, que fue uno de los primeros en finalizarse. Su proyecto (aprobado definitivamente en octubre de 1890) fue redactado por el arquitecto florentino Giuseppe Boccini, dentro de un estilo neorrenacentista (La Nazione, 20 de octubre de 1892: 3). Su fachada principal abre a la plaza, formando así parte de este escenario. Una vez terminado, se instalaron en el palazzo Levi la compañía de seguros La Fondiaria, a principios de $1893^{18}$, y, en su planta baja, dos acreditados cafés: el Centrale (con fachada principal a la plaza y lateral a via dei Brunelleschi),

14 A este respecto, es interesante mencionar que Luigi Del Moro (1845-1897) sucedió a Emilio De Fabris (1808-1883) como arquitecto director de los trabajos de la nueva fachada del Duomo de Florencia (La Nazione, 19 de abril de 1885: 2-3).

15 Giacomo Roster (1837-1905) colaboró en varios proyectos con el arquitecto e ingeniero florentino Giuseppe Poggi (1811-1901). En este sentido, cabe citar que el parque de recreo Tivoli, cuya construcción fue acometida bajo la dirección de Roster entre 18691871, se encuadra dentro del piano d'ingrandimento emprendido por Poggi en Oltrarno (Vázquez, 2018: 75-91).

16 ASCFI, Comune di Firenze, Filza D 3. Centro di Firenze. Vendita di rimanenze dal n. 5 al 7, 1888-1895, fasc. 5 D, núm. 3: "Protocolli. Levi, Ottavio ed Enrico", 1889, CF 7216.

17 Los hermanos Ottavio y Enrico Levi, banqueros de profesión, adquirieron este solar (correspondiente al grupo XVI de los edificios expropiados) en enero de 1889. ASCFI, Comune di Firenze, Filza C 2. Centro di Firenze. Carteggio dal n. 51 al n. 81, 1892-1895, n. reg. 156, c. 142: "Centro di Firenze. Sistemazione di piano stradale in piazza Vittorio Emanuele in via dell'Arcivescovado", CF 7211; y ASCFI, Comune di Firenze, Filza D 3. Centro di Firenze. Vendita di rimanenze dal n. 5 al 7, 1888-1895, fasc. 5 D, núm. 1: "Levi, Ottavio ed Enrico. Vendita di sudetti del grupo 16 del Centro facciate parte del fabbricato del ghetto", CF 7216.

18 La compañía La Fondiaria antes de instalarse en este edificio ocupaba unos locales en la comercial via dei Tornabuoni, núm. 17 (La Nazione, 20 de enero de 1893: 3). 
bajo la dirección de Bartolommeo Pitschen y compañía, quien lo inauguró el 6 de octubre de $1893^{19}$; y el Gilli (con fachada principal a la plaza y lateral a via Roma, núm. 3), en $1917^{20}$.

Los demás inmuebles que fueron delimitando esta vasta plaza se fueron edificando progresivamente con el tiempo. Así, en 1892 se proyectaron los porches de su lado Oeste ${ }^{21} \mathrm{y}$, en 1895, el arquitecto Vincenzo Micheli concluyó su construcción con el arco triunfal central (conocido por la población como el Arcone) ${ }^{22}$, en cuyo ático figura la siguiente inscripción: "L'antico centro della città da secolare squallore a vita nuova restituito. MCCCXCV". Este arco evocaba al mismo tiempo los arcos de triunfo romanos y la entrada monumental de algunas decimonónicas galerías comerciales urbanas.

En 1893 se terminaron las obras del edificio de los hermanos Chiari (en su lado Este, que deslinda con via degli Speziali y via dei Medici), en el que se inauguraría tres años después el Gran Hotel Savoia ${ }^{23}$, y su inmediato, que era propiedad del ingeniero Luigi Buonamici y compañía ${ }^{24}$. Por su parte, los inmuebles del lado Sur de la plaza fueron los últimos en construirse. Esta zona correspondía a los lotes $2^{\circ}$ (perteneciente a los hermanos Paoletti), $3^{\circ}$ (casa dei Castiglioni, situado en medio) y $4^{\circ}$ del grupo XV (de Ernesto Mori, Angiolo Morandi y Pascuale Bertini, entre otros), que delimitan, respectivamente, con via Calimala y via Pellicceria, y en ella intervino el arquitecto Torquato del Lungo ${ }^{25}$. A lo largo de los años de 1895 y 1896 se fueron concluyendo los edificios correspondientes a estos lotes.

En cuanto al lado Sur de la plaza, cabe decir que se tiene constancia documental de que a finales de 1895 existía en su núm. 3 el caffè L'Italia (La Nazione, 21 de diciembre de 1895: 3), y que tres años después la prensa anunciaba en este mismo emplazamiento el café-cervecería fundado por los hermanos Reininghaus (originarios de la ciudad austríaca de Graz). En este local de primera categoría se expendían café, helados, vinos, licores y, sobre todo, cerveza; de ahí que fuera frecuentado especialmente por una clientela procedente de Alemania y Suiza ( $\mathrm{La}$ Nazione, 27 de mayo de 1898: 3$)^{26}$. El café-cervecería Reininghaus desempeñó un papel importante en la vida cultural florentina en los años previos a la Primera Guerra Mundial, cuando se convirtió en punto de encuentro para los poetas y artistas del movimiento futurista, algunos de los cuales también se reunían en otros cafés italianos como el Gran caffè Gambrinus de Nápoles.

En este café-cervecería (en concreto, en su tercera sala) tuvo lugar la fundación de revistas como la literaria Lacerba (por el escritor Giovanni Papini y el pintor Ardengo Soffici), cuyo primer número salió el 1 de enero de 1913, así como otros eventos culturales (Viviani,

19 ASCFI, Comune di Firenze, Filza 2074, 2075. Affari sfogati al tempo del sindaco marchese Pietro Torrigiani. Registro generale cat. $n$. 36-43 dall'1 al 207, 1893, n. reg. 43-219, CF 4320.

20 ASCFI, Comune di Firenze, Permessi per lavori. Reparto città, 1928, fasc. V, ins. 5, CF 8086.

Hasta esa fecha funcionaba una pastelería-confitería con la denominación de Maison Gilli (sita en la planta baja del inmueble de la piazza Vittorio Emanuele II esquina con la via degli Speziali, núm. 6) que había sido instalada por Andrea Gilli en 1893. Por su parte, Luigi Gilli mantenía el comercio de pastelería, confitería, licores y vinos (via Calzaiuoli, núm. 10, esquina con la via delle Oche) fundado en 1733. En 1900 falleció Luigi Gilli, y su hijo mayor decidió vender el negocio a una familia suiza, la de Settimo Frizzoni, que adquirió también el local Gilli de la via degli Speziali. Bajo su gestión los dos establecimientos formaron un solo grupo, conocido con el nombre de Luigi Gilli, hasta la desaparición del emplazado en la via degli Speziali. El negocio de la via Calzaiuoli se destinaba para la venta de dulces y chocolate mientras que el nuevo café de la plaza Vittorio Emanuele II era el lugar preferido de encuentro de la sociedad acomodada florentina. La familia Marchetti adquirió en 1974 la cafetería de los núms. 100-104 de via Calzaiuoli y la transformó en lo que es hoy: un snack self-service. Por su parte, el café de la actual piazza della Repubblica ha ido cambiando de gestión con el tiempo, introduciéndose reformas que han modificado su aspecto primitivo (Il caffé Gilli nel cuore di Firenze, 2007: 30, 37 y 42).

21 La zona de los porches corresponde a los lotes XI y XII del plan de reordenación del centro de Florencia y en ella intervino el arquitecto Vincenzo Micheli (1833-1905), conforme a su proyecto fechado el 28 de junio de 1889. ASCFI, Comune di Firenze, Filza D 4. Centro di Firenze. Vendita di rimanenze n. 8, 1889-1905, fascs. 8 D, p. 2 y 8 D, p. 55, CF 7217.

22 Este arco se corona con un ático con balaustrada (que inicialmente no estaba programada) y con cuatro esculturas que son representaciones alegóricas de las Bellas Artes. Fueron realizadas en el estudio de Vincenzo Rosignoli. ASCFI, Comune di Firenze, Filza D 4. Centro di Firenze. Vendita di rimanenze n. 8, 1889-1905, fasc. 8 D, p. 69, CF 7217.

23 ASCFI, Comune di Firenze, Filza A XII. Centro di Firenze. Carteggio dal n. 608 al n. 713, aff. 635, CF 7173.

El 2 de marzo de 1896 tuvo lugar la inauguración del Gran Hotel Savoia (en la actualidad, Hotel Savoy), que fue construido conforme al proyecto del arquitecto Vincenzo Micheli. A finales de 1925 se redactó un proyecto para elevar un piso más en altura este edificio. ASCFI, Comune di Firenze, Permessi per lavori. Reparto città, 1928, fasc. V, ins. 5, CF 8086; y (La Nazione, 2 de marzo de 1896: 2).

24 ASCFI, Comune di Firenze, Filza D 1. Centro di Firenze. Vendita di rimanenze dal n. 1 al n. 4, 1884-1888, fasc. 3 D, CF 7214.

25 ASCFI, Comune di Firenze, Filza D 7. Centro di Firenze. Vendita di rimanenze dal n. 21 al n. 25, 1893-1898, aff. 23 D: "Del Lungo Arch. Torquato per Paoletti, Fratelli, Morandi, Angiolo ed altri”, CF 7220.

26 A mediados de la década de los años diez del siglo pasado el local contiguo a esta café fue ocupado por el bar Imperial de Donnini (piazza Vittorio Emanuele II esquina con la via Pellicceria), que poco después se denominó caffè Donnini (Ventinove, 1920-1921: 210). 
1964: 27-31) $)^{27}$. Fue en esos momentos, y bajo la gestión del alemán Andrea Juon, cuando pasó a conocerse como caffè delle Giubbe Rosse (en alusión a los smokings o chaquetas de color rojo y delantal blanco que llevaban sus camareros), denominación que mantiene en la actualidad. Desde entonces fue considerado como el café literario por excelencia. De hecho, siguió contando con la presencia de personalidades en este ámbito como el poeta Eugenio Montale, que llegó a Florencia en 1929 y conformó en este centro -transformado en una especie de "convento literario"- y en torno a él una tertulia integrada por poetas, críticos y teóricos como Carlo Bo, Mario Luzi, Piero Bigongiari u Oreste Macrì, figuras emblemáticas del hermetismo italiano (Macrì, 1991: 4).

Pronto la nueva plaza se convirtió en lugar preferente de encuentro social y cultural para la sociedad burguesa de la época, es decir, en un «salón urbano» al aire libre muy animado por sus cafés: Centrale (que se denominó posteriormente Paszkowski) ${ }^{28}$, Reininghaus (actual Le Giubbe Rosse) y Gilli ${ }^{29}$, que están vinculados con el recuerdo de artistas y literatos. A éstos se sumó el Gambrinus, a cuyo estudio dedicamos el siguiente apartado.

\section{UN CAFÉ-CERVECERÍA QUE RINDIÓ CULTO AL MÍTICO GAMBRINUS}

En la única zona porticada de la piazza Vittorio Emanuele II (correspondiente a su sector Oeste) y, en concreto, en el solar donde estuvo situada la antigua Loggia del Pesce, se instaló el fastuoso Gambrinus Halle (via dei Naccajoli -hoy via dei Brunelleschi-, núm. 1, esquina con la via della Nave -actual via del Campidoglio-), que fue inaugurado el 29 de noviembre de 1894 (FIGURA 4) ${ }^{30}$.

Una de las especialidades de este establecimiento, además de los ponches y los helados, era la cerveza, bebida cuyo consumo se extendió en Europa a partir de finales del siglo XIX al mismo tiempo que se lograron aportaciones notables para la industria cervecera. De ahí que, y como reflejaba su denominación, pretendiera rendir tributo al legendario Gambrinus, un experto cervecero protegido por el monarca Carlomagno. La tradición lo proclama "rey de la cerveza" y aparece representado con cara regocijada, destacada barriga y sosteniendo una jarra de cerveza espumosa o una taza con una de sus manos y, algunas veces, con un barril cerca (Martínez, 1996: 27).

En el siglo XIII tuvo lugar la formación de la corporación de los cerveceros, que eligieron como patrón a Gambrinus y, desde entonces, aunque con momentos de decaimiento a favor del vino como referente europeo inevitable, el consumo de esta bebida se ha difundido por todo el mundo (Hoja oficial de la provincia de Barcelona, 24 de octubre de 1927: 13).

La figura de Gambrinus adquirió relevancia en el último tercio del siglo XIX gracias a su propagación a través de cuentos y narraciones. Así, el relato fantástico "La pesca milagrosa" (1862) (dentro de la antología Cuentos de las orillas del Rin), de los escritores franceses Émile Erckmann y Alexandre Chatrian, se publicó a modo de folletín en la prensa periódica europea entre mediados de los años sesenta y principios de los ochenta ${ }^{31}$. En ese relato las tabernas no son meros lugares de paso sino santuarios de secretos, custodiados por seres de leyenda como el temido Herodes Van Gambrinus -apodado el Baco del Norte- con "las mangas de la camisa remangadas hasta por encima del codo, mostrando al aire sus brazos peludos, moviéndose entre las jarras relucientes, las mejillas enormes apoyadas sobre los puños formidables, con la espesa pelambrera roja enmarañada y la larga barba amarilla derramándose sobre su pecho" (Erckmann y Chatrian, 1944: 86).

27 De hecho, entre los eventos que se gestaron en este café, es interesante aludir a la serata futurista que se celebró en el teatro Verdi de Florencia el 12 de diciembre de 1913. Para un estudio en mayor profundidad de los literatos y artistas que frecuentaron este café, como los otros dos citados ubicados en esta plaza, se recomienda la consulta de: (Falqui, 1962: 451-552).

28 En 1907, al igual que el Gambrinus, comenzó a ser gestionado por la Sociedad Toscana anónima C. Paszkowski por lo que recibió el nombre de caffè Paszkowski, en honor a su dueño de procedencia polaca. ASCFI, Comune di Firenze, Repertorio generale di affari dell'anno 1907 dalla lettera M alla lettera Z, n. reg. 198-15, CF 2990. Este café cobró mayor protagonismo en el panorama cultural en los años treinta, cuando un grupo de literatos se reunía en él todas las tardes para intercambiar opiniones, encontrándose entre los asistentes Mario Luzi, Alessandro Parronchi, Piero Bigongiari y Pier Francesco Marcucci (Casadei, 1969: 11).

29 El Gilli acogió tertulias literarias y artísticas como las organizadas por los pintores del grupo del Novecento florentino. En los años treinta, sus propietarios se hicieron cargo también del Paszkowski.

30 ASCFI, Fondo disegni, Caffè Gambrinus (portici), AMFCE, 1513 (cass. 51, ins. A).

31 A esta respecto, hay que mencionar, entre otros periódicos, los siguientes: (Crónica de Badajoz, 18 de julio de 1866: 3-4) y (Diario de Lugo, 14 de de octubre de 1882: 3). 


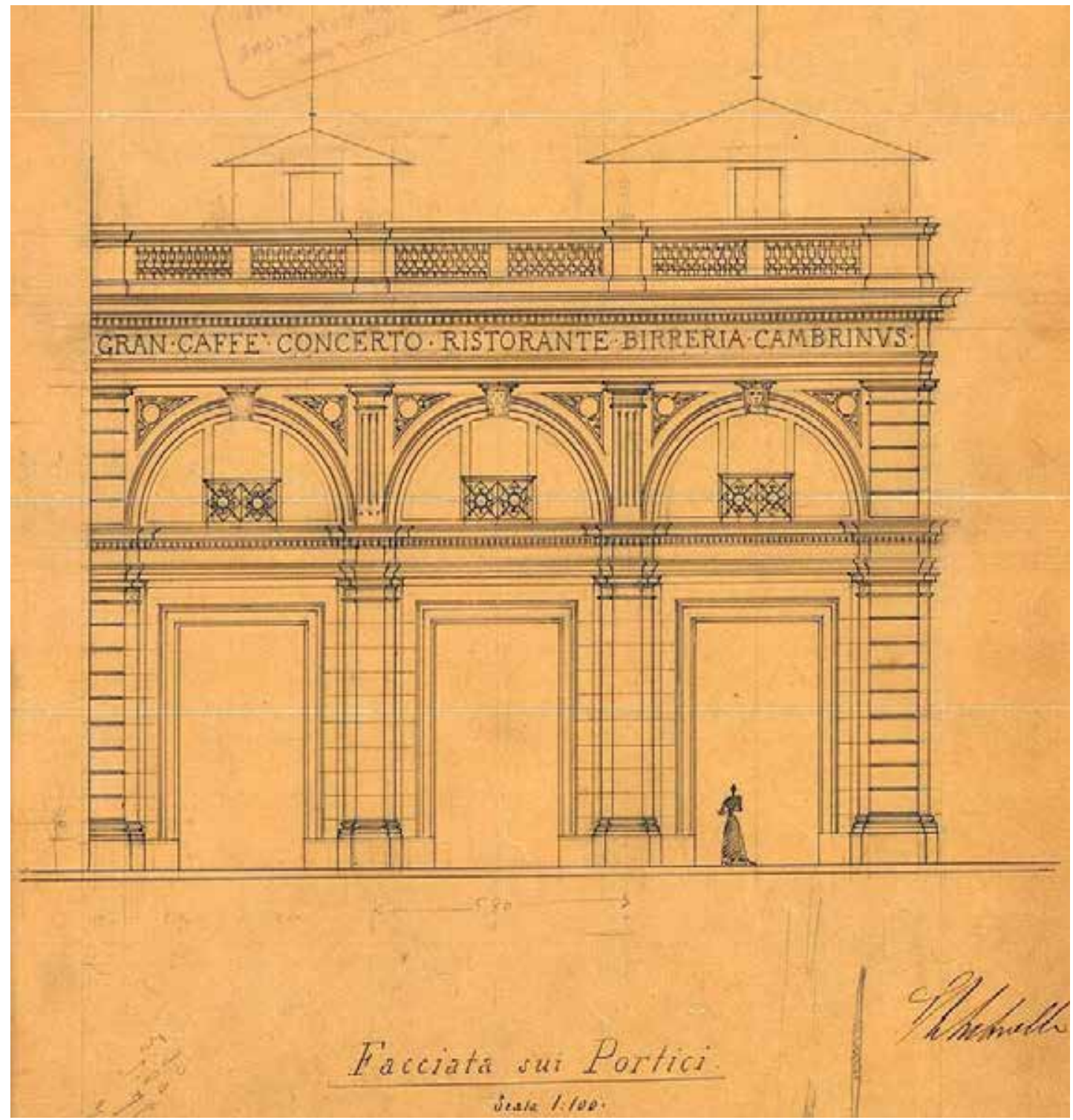

FIGURA 4. Fachada principal del café-cervecería Gambrinus (via dei Brunelleschi). 1893. ASCFI

En esta misma línea, el autor francés Charles Deulin había escrito la historia titulada Gambrinus, rey de la cerveza ${ }^{32}$, que contiene cinco narraciones en torno a las emocionantes pericias de sus protagonistas, uno de ellos Gambrinus, feliz inventor de esta bebida, a quien sus súbditos veneran con admiración (Diario de Burgos, 18 de septiembre de 1956: 6). De hecho, en honor a este patrón, los aficionados a la cerveza de la ciudad de Berlín organizaron, a mediados del mes de octubre de 1896, una original peregrinación de ocho días a las principales fábricas de cerveza alemanas y austriacas (El Cantábrico, 14 de octubre de 1896: 2).

El nombre de Gambrinus fue utilizado como reclamo comercial en el mercado de la cerveza y de su industria, así como su fama impulsó que se erigiesen «monumentos» en su honor, en forma de establecimientos o de estatuas, en varias ciudades (El Eco de Santiago, 13 de febrero de 1905: 1).

Una de esas capitales fue Florencia, cuya sociedad acomodada demandaba nuevos modos de ocio y de consumo. El Gambrinus fue proyectado por el arquitecto e ingeniero Giacomo Roster en 1893, por encargo de su propietario Spirito Giamello. Fue levantado en un solar de trazado rectangular y con desarrollo en profundidad. Presentaba plantas sótano, baja, mezzanino y terraza. 


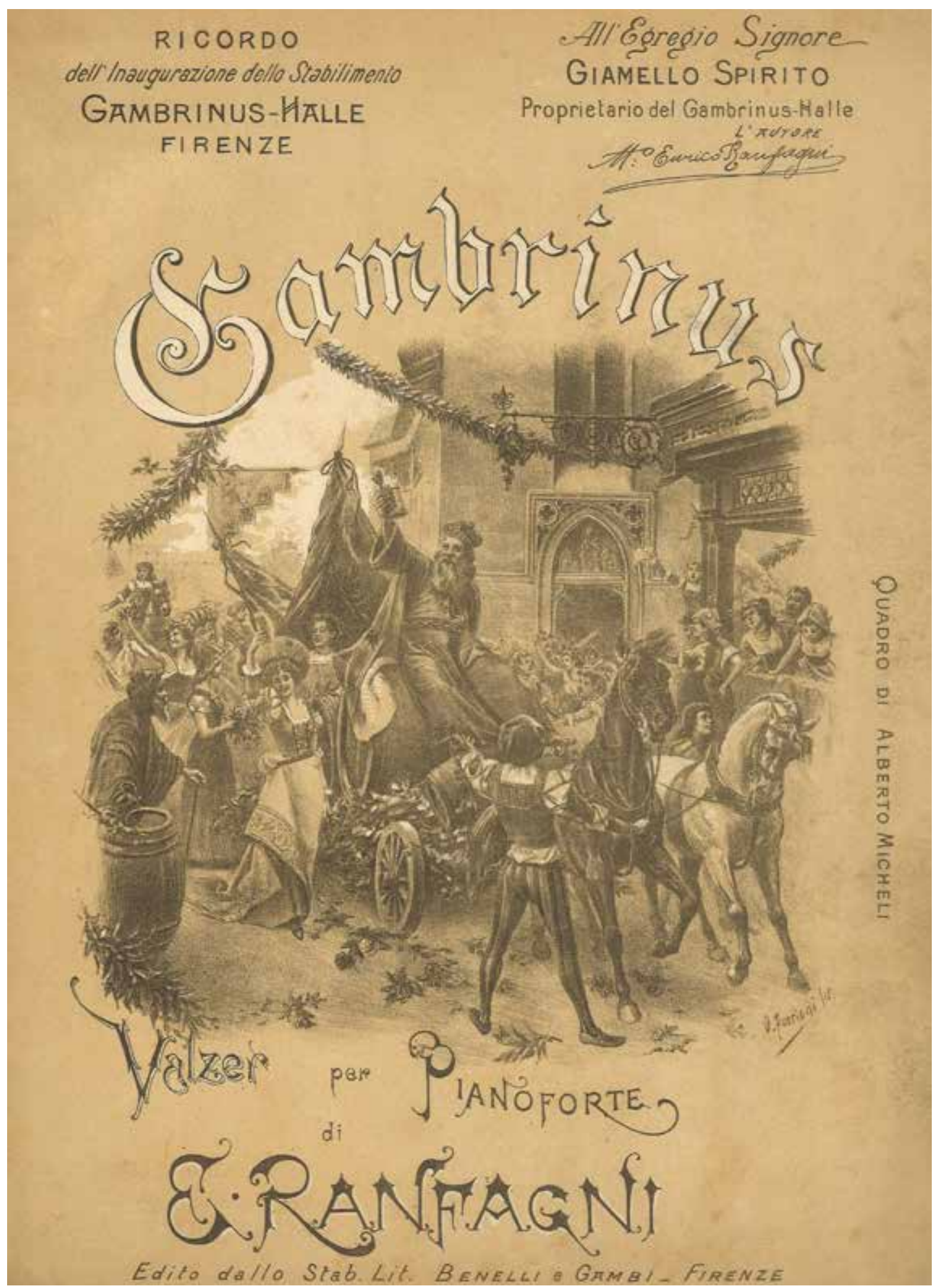

FIGURA 5. Partitura dedicada por Enrico Ranfagni a Spirito Giamello, propietario del Gambrinus. 1894.

Colección privada

Este local fue inaugurado el 29 de noviembre de 1894 por el alcalde de la ciudad, el marqués Pietro Torrigiani, aunque su apertura al público no tuvo lugar hasta el 1 de diciembre, a las 20:00 horas (La Nazione, 1 de diciembre de 1894: 3). Para esta ocasión el maestro Enrico Ranfagni compuso un vals de piano titulado "Andiamo al Gambrinus? Si" con la finalidad de deleitar a los asistentes (FIGURA 5) ${ }^{33}$.

33 La portada de la partitura $(34$ × $25 \mathrm{~cm})$, que fue dedicada por Ranfagni a Giamello como recuerdo del día de la inauguración del Gambrinus, se ilustró con el cuadro de Alberto Micheli que decoraba su interior. Sobre este pintor, hijo de Vincenzo Micheli y nacido en Florencia en 1870, véase, entre otras publicaciones: (Pallottino, 1991). 


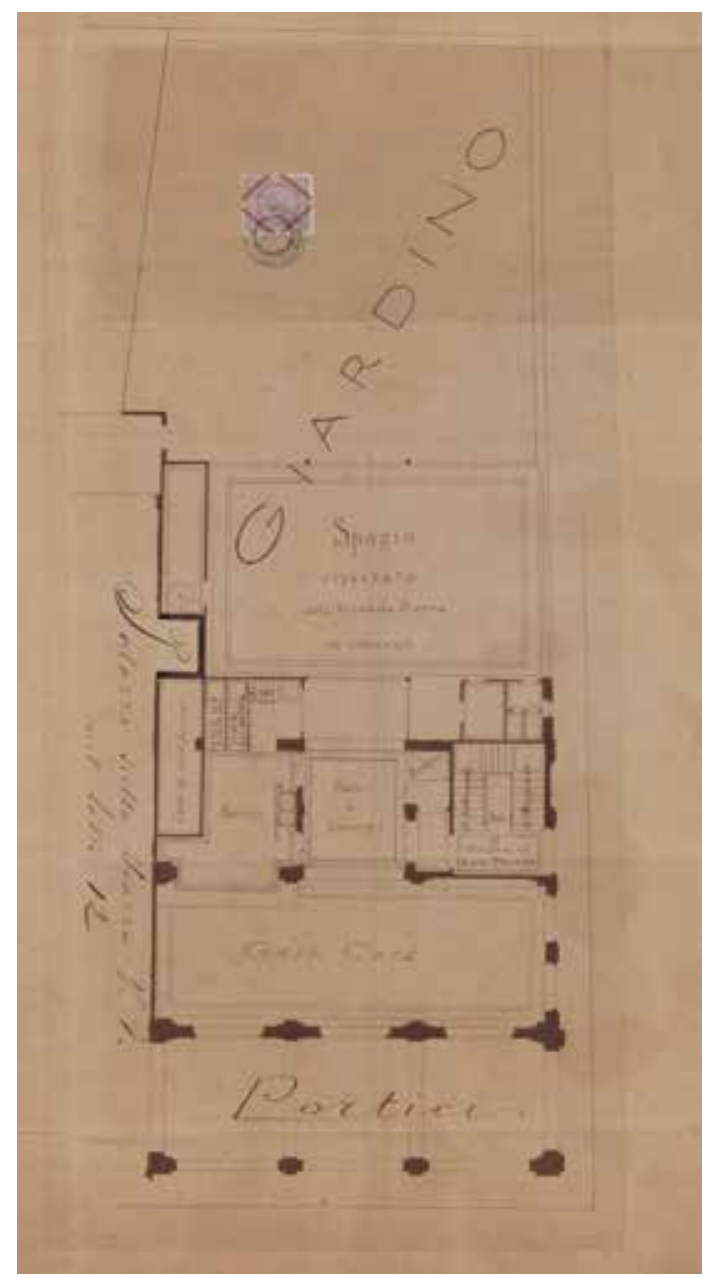

FIGURA 6. Proyecto. Planta baja del café-cervecería Gambrinus. 1893. ASCFI
Su planta sótano comprendía, entre otras estancias, una cocina, una bodega y una sala de billar ${ }^{34}$. Por su parte, a la planta baja se podía acceder desde cualquiera de los tres arcos de medio punto del pórtico (abierto en via dei Brunelleschi y con las recurrentes referencias clasicistas), que conducían a un amplio salón denominado Gran Café, que tenía planta rectangular (FIGURA 6) ${ }^{35}$. Sus paredes se recubrían, conforme a los gustos de la época, con espejos y mármoles. Este diáfano y lujoso salón se hallaba decorado con un cuadro de Alberto Micheli que representaba el triunfo de Gambrinus ${ }^{36}$ y con una fuente en el centro, que fue realizada por el escultor Vincenzo Rosignoli ${ }^{37}$. Micheli plasmó a Gambrinus según la leyenda, es decir, como «rey de la cerveza». Así, fue representado como un personaje barbudo y alegre, con una corona en la cabeza y una jarra de cerveza en su mano derecha. Aparecía sentado sobre un barril, a modo de trono, que era transportado por un carro tirado por dos caballos. Su parte delantera se adornaba con flores y barriles de cerveza, que eran repartidos entre el público que le aclamaba y arrojaba flores a su paso. La ambientación de la escena, así como la indumentaria de los protagonistas, estaba inspirada en la Edad Media.

En 1895, el salón llamado Gran Café

fue ornado también con un cuadro del admirado artista Cipriano Cei (1867-1922, entonces asentado en Florencia), que representaba alegóricamente el licor como bebida de signo social elevado ${ }^{38}$, mediante una dama que aparecía degustando plácidamente un coñac de una prestigiosa marca (La Nazione, 24 de marzo de 1895: 2). Estas obras ponen de manifiesto la importancia que en la época había alcanzado la pintura decorativa en los locales de carácter público (teatros, cafés, etc.) para el deleite de su clientela. De hecho, el techo del Gilli fue decorado igualmente con cuatro frescos del pintor Ezio Giovannozzi (1882-1964), que plasman mujeres distinguidas de Francia (entre ellas, Paolina Bonaparte y Madame Récamier) de acuerdo con la estética modernista (Vázquez, 2015: 43).

Asimismo, este salón comunicaba con un jardín situado al fondo. Desde esta planta se podía acceder a las superiores y a la terraza, desde donde se podía contemplar una panorámica de la renovada plaza.

El mezzanino acogía un amplio salón, cuyas dimensiones coincidían con el del piso inferior, en torno al cual se articulaban estas dependencias: servicios higiénicos, cuatro

34 El 30 de diciembre de 1894, los propietarios de este establecimiento obtuvieron licencia municipal para colocar una reja de hierro en la zona de la acera correspondiente a la via della Nave (hoy via del Campidoglio) con la finalidad de poder ventilar sus locales subterráneos (y, especialmente, la sala de billares). ASCFI, Filza D 4. Centro di Firenze. Vendita di rimanenze n. 8, 1889-1905, fasc. 8 D, p. 65, CF 7217.

35 ASCFI, Fondo disegni, Caffè Gambrinus (piano terreno), AMFCE, 1589 (cass. 52, ins. D).

36 El lienzo de Micheli desapareció en una de las reformas realizadas en este establecimiento para ser destinado a otros usos, pero se puede saber qué representaba gracias a la ilustración que figura en la partitura de Ranfagni (figura 5).

37 Vincenzo Rosignoli (1856-1920) nació en Asís y residió durante varios años en Florencia, donde falleció. Se encargó de la decoración de muchos edificios florentinos.

38 En este período se abandonaron las representaciones religiosas y de temática histórica cultivadas en los dos siglos anteriores (Alba, 2001: 759-784). 


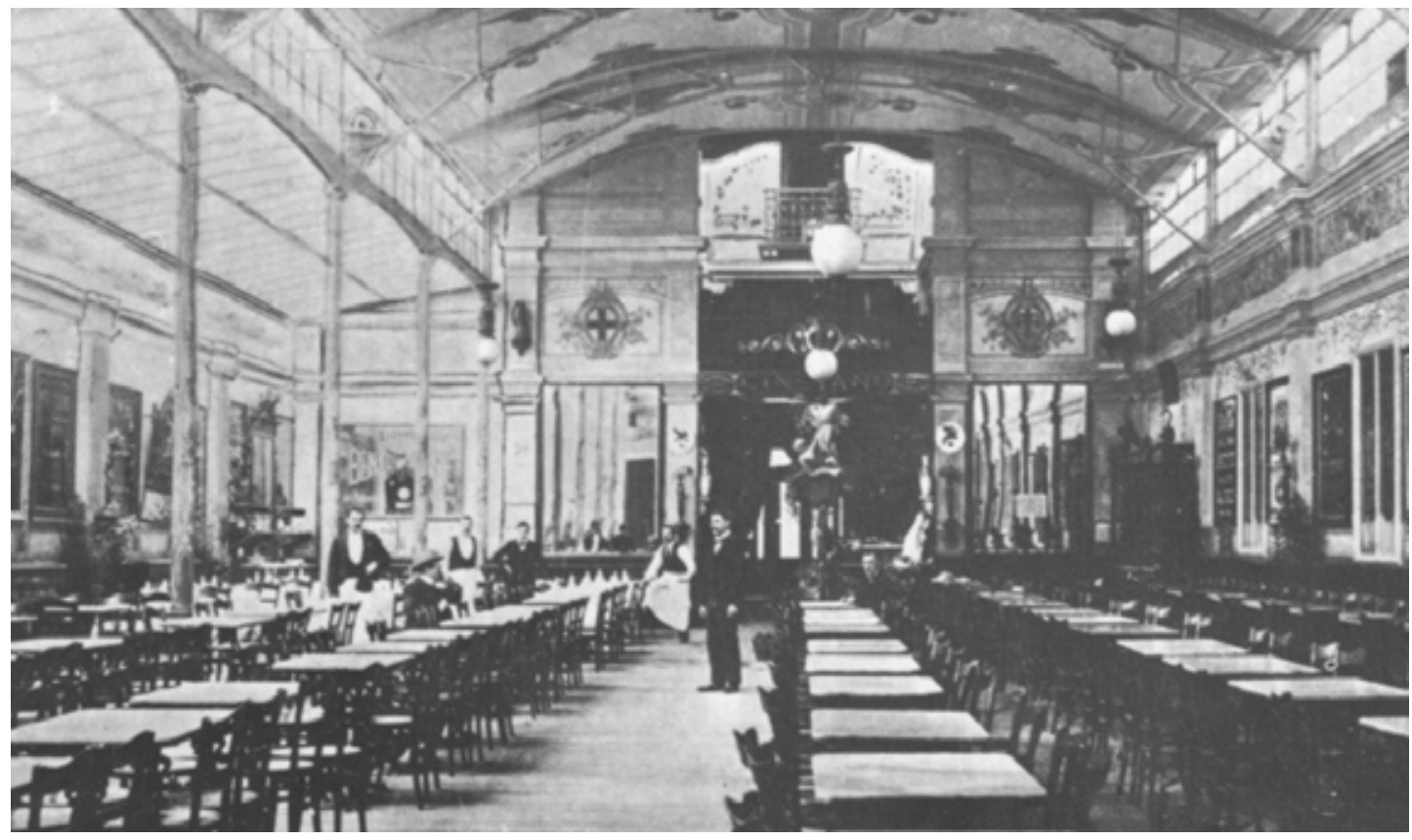

FIGURA 7. Vista del interior del gran salón del café-cervecería Gambrinus. Principios del siglo XX. ASCFI

estancias reservadas y un palco para las actuaciones musicales. Este café organizaba con éxito veladas musicales que durante la estación de verano podían disfrutarse en el jardín, amenizando a los concurrentes. Así, este nuevo local se sumaba a la moda de los espectáculos variados y de música que se ofrecían en los elegantes cafés-conciertos denominados Alhambra (piazza Beccaria esquina con el viale Carlo Alberto -hoy viale della Giovine Italia-, que fue inaugurado por Torquato Montelatici y compañía el 5 de junio de 1889) ${ }^{39}$; Trianon (propiedad de Torquato Montelatici, sito en la via degli Speziali, núm. 3, y piazza Vittorio Emanuele, núm. 1) ${ }^{40}$, que, a pesar del éxito de sus representaciones y de su restaurante ${ }^{41}$, tuvo que cerrar definitivamente sus puertas el 8 de marzo de 1896 ante la quiebra económica de su dueño ${ }^{42}$; o Savonarola (de Cesare Bartollini, situado en los porches de piazza Cavour, núms. 1-2), ubicado, respecto a los anteriormente citados, un poco distante del centro histórico (Ventinove, 1893: 166).

Además, contaba con una sección para cervecería y con servicio de restaurante en la planta principal. Durante la estación de verano se colocaban veladores bajo el pórtico para acoger a su clientela durante el buen tiempo ${ }^{43}$.

Este establecimiento fue denominado Gambrinus Halle porque fue ideado con unas amplias dimensiones que fueron logradas por el empleo del hierro y del vidrio en su construcción, siguiendo así las tendencias en boga en aquellos momentos y evocando el modelo de las Halles parisinas o de la Galleria Vittorio Emanuele II de Milán, así como de algunos cafés, que también recurrieron a esta tipología constructiva como, por ejemplo, el parisino café Les Deux Magots (plaza de Saint-Germain-des-Prés, núm. 6). De hecho, llegó a ser el café más grande de Florencia, con una capacidad para 1.300 personas, así como uno de los mayores de Europa.

39 (La Nazione, 7 de junio de 1889: 3). Después de la Segunda Guerra Mundial este establecimiento fue destinado a cine al aire libre y en 1961 desapareció para convertirse en la sede del periódico La Nazione (Serra, 2000: 129).

40 El Trianon fue instalado en 1893 en la planta baja del edificio construido por el arquitecto Luigi Buonamici, donde hoy se encuentran los grandes almacenes La Rinascente (La Nazione, 28 de marzo de 1893: 4).

41 Este elegante establecimiento era muy concurrido por la sociedad florentina (La Nazione, 21 de octubre de 1893: 3).

42 (La Nazione, 17 de noviembre de 1895: 3) y (La Nazione, 9 de marzo de 1896: 1). Sus locales fueron reformados por los hermanos Bocconi para destinarlos a comercio de venta de muebles, ropa, etc. Su apertura tuvo lugar el 31 de marzo de 1897 (La Nazione, 31 de marzo de 1897: 4).

43 El 5 de agosto de 1895, el gestor de este establecimiento, Andrea Cavagnaro, solicitó licencia municipal para poder ocupar en horario de tarde, con mesas y sillas, el suelo público en $20 \mathrm{~m}^{2}$ en la piazza Vittorio Emanuele II. Pocos días después le fue concedido el pertinente permiso. ASCFI, Filza 2301. Affari sfogati al tempo del sindaco marchese Pietro Torrigiani. Registro generale dal n. 4801 al n. 5000, 1895, aff. núm. 4.803, CF 4485. Igualmente, el 5 de octubre de 1895, se le dio autorización para ampliar la verja de este local instalada en su exterior. ASCFI, Filza D 4. Centro di Firenze. Vendita di rimanenze n. 8, 1889-1905, fasc. 8 D, núm. 68, CF 7217. 
A diferencia de los antiguos cafés, sus dependencias y, especialmente, sus dos salas eran espacios diáfanos y bien iluminados con ventanales que permitían la entrada de luz natural y una transición fluida entre exterior e interior. Su salón principal se hallaba conformado por dos ámbitos, uno de ellos, más reservado y delimitado por una hilera de columnas de hierro y con cubierta de vidrio (FIGURA 7). En su interior se disponían muchas mesas de mármol con sus sillas de madera (distribuidas a través de la empresa Thonet) ${ }^{44} \mathrm{y}$ divanes de terciopelo rojo. Por tanto, fue instalado con todo lujo, con pinturas, con cómodos divanes que invitaban a la charla relajada, con grandes espejos y con un refinado servicio atendido por mozos uniformados.

De este modo, respondía al modelo de café configurado en el último cuarto del siglo XIX, es decir, amplio, fastuoso, acogedor, luminoso y atento a las tendencias constructivas del momento, en la línea de otros cafés europeos como el Suizo de Madrid (calle de Alcalá, núm. 36, esquina con la Ancha de Peligros -luego calle de Sevilla-, núm. 16, fundado en 1845 por Francisco Matossi, Bernardo Fanconi y compañía) ${ }^{45}$ o el de Ambos Mundos (paseo de la Independencia, núms. 30-32, inaugurado el 3 de octubre de 1881) de Zaragoza. Este último disponía de 208 mesas de mármol con sus sillas de madera (de la empresa Thonet) para servir a unas 1.800 personas y estaba considerado en su época como el más grande de Europa (Vázquez, 2015: 72-77).

Como hemos mencionado anteriormente, en este café-cervecería se ofrecían magníficos conciertos por reputados concertistas y otros espectáculos variados y se celebraban eventos culturales que ponían de manifiesto que estaba al tanto de las últimas novedades. Así, en noviembre de 1899 fue elegido para realizar la primera exposición pública del cinematógrafo de los hermanos Lumière, cuatro años después de su invención (La Nazione, 19 de febrero de 1901: 3).

El Gambrinus era elogiado como cuartel general de escritores y de artistas, que acudían también a Le Giubbe Rosse. De hecho, como constata Giuseppina Rossi, en los primeros años de la Primera Guerra Mundial se reunieron en él algunos integrantes del movimiento futurista como Emilio Settimelli, Bruno Corra, Remo Chiti y Mario Carli (Rossi, 1988: 59), con el fin de extender los ideales del Futurismo a través del teatro y del cine, elevados a instrumentos privilegiados de propaganda bélica (Martínez-Peñuela, 1995: 123). Luego este grupo pasó del Gambrinus al próximo café-cervecería Mucke (abierto en 1905 en la via dei Lamberti, núm. 5, esquina con la via Pellicceria) (Vázquez, 2015: 45).

Igualmente, se convirtió en lugar de referencia de figuras destacadas del momento $y$, entre las personalidades que frecuentaron este centro se encuentra Guillermo, príncipe imperial de Alemania, que, junto con su prometida la duquesa Cecilia de Mecklemburgo, hizo una parada en el mismo en febrero de 1905 cuando visitaron la ciudad ( $\mathrm{La} \mathrm{Cruz}, 22$ de febrero de 1905: 3).

A partir de su inauguración se fueron acometiendo obras menores y de mantenimiento que modificaron su aspecto primitivo. Así, con fecha de 6 de noviembre de 1901, Alessandro Tappari, uno de los propietarios del Gambrinus, solicitó permiso municipal para acometer obras de limpieza y rehabilitación de pintura en sus fachadas, que le fue concedido el 27 de noviembre de ese año. Los trabajos comenzaron a principios de marzo de $1902^{46}$, y se vieron seguidos por la restauración de la cubierta de vidrio en junio de 1903. Siete años después, se procedió a la apertura de cuatro vanos en la pared del lado del salón, que abría a la via del Campidoglio ${ }^{47}$.

El Gambrinus fue destinado a café, cervecería y restaurante hasta comienzos de la década de los veinte de la pasada centuria, bajo la dirección de Luigi Orlandi (Ventinove, 19201921: 212 y 216). Sin embargo, la carencia de solvencia económica de su propietario condujo a su cierre. Se tiene constancia documental de que el consistorio municipal concedió licencia,

\footnotetext{
44 Los muebles de la empresa Thonet se vendían en la fábrica A. Targini (via degli Alfani, núm. 57) de esta ciudad (La Nazione, 28 de enero de 1877: 4)

45 Sobre la historia y el devenir del desaparecido café Suizo de Madrid se recomienda la consulta de: (Vázquez, 2019: 95-112).

46 ASCFI, Filza D 4. Centro di Firenze. Vendita di rimanenze n. 8, 1889-1905, fasc. 8 D, p. 75, CF 7217.

47 ASCFI, Permessi per lavori 1910. Sezione città e reparti 1-3 e 5, fasc. C, ins. 2 m, CF 7989.
} 


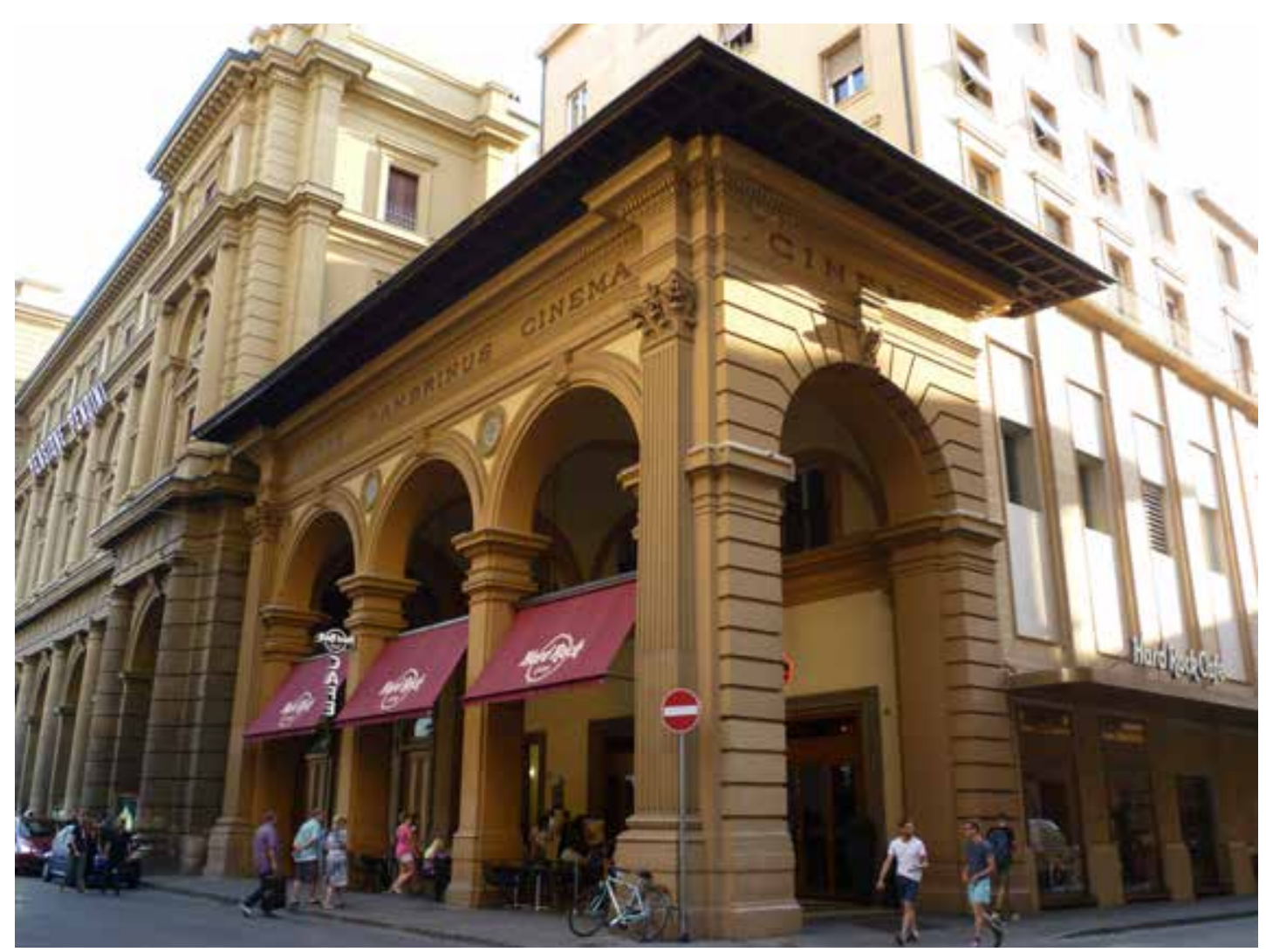

FIGURA 8. Exterior del antiguo café-cervecería Gambrinus (via dei Brunelleschi, núm. 1, esquina con la via del Campidoglio). 2018. Autora

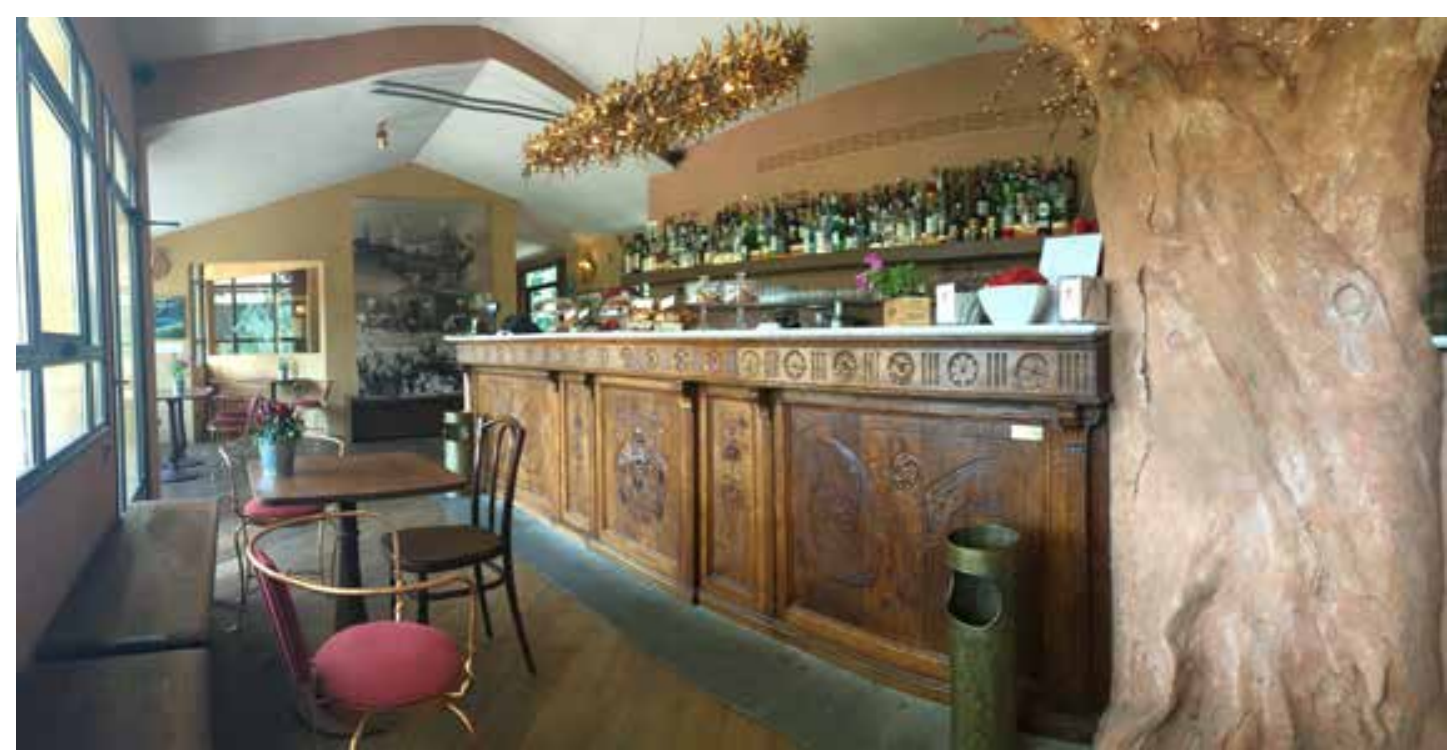

FIGURA 9. Barra del antiguo café-cervecería Gambrinus en el chalet fontana. 2018. Autora

el 24 de agosto de 1921, para que fuera destinado a sala de cinematógrafo con el título de Gambrinus $^{48}$, y respondiendo así a la notable demanda de nuevos cines que se produjo en esos años. Fue renovada en 1936 y tres años después abrió sus puertas como Cinema Olimpia, denominación que mantuvo hasta abril de 1944, momento en el que recuperó su antiguo nombre de Gambrinus (Batini, 1976: 308). En la actualidad, en las salas del histórico café se encuentra un Hard Rock café (via Brunelleschi, núm. 1, esquina con la via del Campidoglio) (FIGURAS 8-9) ${ }^{49}$.

48 ASCFI, Comune di Firenze, Permessi per lavori, 1921. Reparto città, fasc. C, ins. 1, CF 8016.

49 De este antiguo café se conserva su barra, fabricada en madera y tallada (con el motivo decorativo de un grifo que sostiene con sus garras un escudo), que luce hoy en día en el chalet Fontana (viale Galileo Galilei, núm. 7) de Florencia (figura 9). 


\section{CONCLUSIONES}

Con la fundación del café-cervecería Gambrinus, Florencia contó con un establecimiento dedicado al legendario rey germánico a quien los pueblos del Norte atribuyen la invención de la cerveza, y al igual que los que se abrieron con este mismo nombre en otras ciudades europeas. A este respecto, cabe destacar los creados en Barcelona (esquina de la Rambla con el pasaje de la Banca) el 31 de julio de $1881^{50}$; en Zaragoza (plaza de la Constitución -hoy plaza de España-, núm. 1), el 28 de mayo de 1889 por Pablo Gili51; Alfaro (plaza Mayor, propiedad de Cristóbal Marín), en 190152; Gijón, el 1 de mayo de 190853; o Valencia (plaza del Príncipe Alfonso, núm. 8) $)^{54}$; así como el célebre Gran caffè Gambrinus de Nápoles, que fue inaugurado el 1 de noviembre de 1890 en pleno centro urbano (piazza Trieste y Trento) y desempeñó un papel fundamental en la vida napolitana como escenario cultural-artístico ${ }^{55}$.

El fastuoso Gambrinus fue uno de los grandes cafés históricos florentinos, que se instaló en el «renovado corazón de la ciudad», en la piazza Vittorio Emanuele II, y contribuyó a que se convirtiera en un verdadero «salón urbano» para la sociedad burguesa. Destacó por sus amplias dimensiones y su elegante decoración, llegando a ser considerado como uno de los más grandes de Europa. A diferencia de sus homólogos, congregó a una clientela especializada en el consumo de cerveza, a la que deleitaba al mismo tiempo con conciertos musicales y otras representaciones. Igualmente, fue escenario de reuniones de escritores y artistas comprometidos con la vanguardia, convirtiéndose así en un local à la page. Lamentablemente, y al igual que otros cafés de la época, no sobrevivió a la lenta destrucción que conlleva el paso del tiempo y a la transformación de las prácticas de ocio florentinas.

50 Como señala Paco Villar, el dueño de la cervecería Gambrinus de la calle del Portal de Santa Madrona, Valentì Pons, inauguró el 31 de julio de 1881 una lujosa cervecería, café y restaurante con el mismo nombre en la esquina de la Rambla con el pasaje de la Banca. La especialidad de la casa eran las cervezas (Villar, 2013: 17-18). Este establecimiento cerró sus puertas en mayo de 1910 (El Bien Público, 1 de junio de 1910: 2).

51 Este café-cervecería se instaló en un local anteriormente ocupado por el café Español y luego por una horchatería, al estilo de las modernas brasseries de París (Vázquez, 2015: 78-84).

52 En 1901, el artista Gregorio González pintó al temple un cuadro para esta cervecería, que anunciaba el café Moka, dentro de un estilo deudor del Modernismo (La Rioja, 8 de noviembre de 1901: 1).

53 Este establecimiento abrió sus puertas bajo la dirección de Ramón Canivell (propietario también de la acreditada cervecería Lion d'Or) (El Independiente, 16 de mayo de 1908: 3).

54 Este local estaba dirigido en 1931 por Lorenzo Marín (Las Provincias, 15 de marzo de 1931: 28).

55 Este café-cervecería fue emplazado en el lugar donde anteriormente estuvo el Gran Café, que fue inaugurado en 1864 y estuvo en funcionamiento hasta 1889. Poco después, fue adquirido por el empresario Mariano Vacca, quien tras reformarlo (conforme al proyecto del prestigioso arquitecto Antonio Curri, que unía el ambiente aristocrático del antiguo café con el de la bohémien cervecería Estrasburgo) lo convirtió en el célebre Gambrinus (AA.VV., 1989: 118) y (Mangone, 2008: 14-16 y 31). 


\section{BIBLIOGRAFÍA GENERAL}

- AA.VV. (1896). Firenze d'oggi. Firenze: Tipografia di Enrico Ariani.

- AA.VV. (1989). Il caffe, storia e cultura. Roma: La Meridiana.

- Alba Pagán, E. (2001). La pintura y los pintores valencianos en las 'Casitas' del Real Sitio de San Lorenzo del Escorial: Mariano Salvador Maella, Benito Espinós, Miguel Parra, José López Enguídanos y Mariano Sánchez. En Campos y Fernández de Sevilla, F. J. (coord.). El Monasterio del Escorial y la pintura, Actas del Simposium. San Lorenzo de El Escorial: Real Centro Universitario Escorial-María Cristina, 759-784.

- Batini, G. (a cura di) (1976). Album di Firenze, vol. II. Firenze: La Nazione.

- Bonet Correa, A. (2012). Los cafés históricos. Madrid: Cátedra.

- Carocci, G. (1886). Il ghetto di Firenze e i suoi ricordi. Firenze: Galletti e Cocci tipografi editori.

- Casadei Matteotti, L. (1969). I caffè fiorentini. Firenze: Tip. Meschini.

- Cecioni, A. (1905). Scritti e ricordi. Firenze: Tipografia Domenicana.

- Cozzi, M. y Carapelli, G. (1993). Edilizia in Toscana nel primo Novecento. Firenze: Edifir.

- Cresti, C. y Zangheri, L. (1978). Architetti e Ingegneri nella Toscana dell'Ottocento. Firenze: Uniedit.

- Cruz Valenciano, J. C. (2014). El surgimiento de la cultura burguesa. Personas, hogares y ciudades en la España del siglo XIX. Madrid: Siglo XXI de España Editores, S.A.

- Detti, E. (1977). Firenze scomparsa. Firenze: Vallecchi editore.

- Erckmann, É. y Chatrian, A. (1944). Cuentos de orillas del Rhin. Madrid: Espasa-Calpe, S.A.

- Falqui, E. (1962). Caffè letterari, vol. II. Roma: Canesi Editore.

- Fanelli, G. (2002). Firenze. Architettura e città, vol. I. Firenze: Mandragora.

- Guereña, J. L. (2003). Espacios y formas de sociabilidad en la España Contemporánea. Hispania, LXIII/2, 214, 409-414.

- Il caffè Gilli nel cuore di Firenze (2007). Firenze: Giunti.

- Mangone, F. (coord.) (2008). Il Gambrinus a Napoli. Napoli: Paparo Edizioni.

- Martínez Laínez, F. (1996). La Cerveza en España. Madrid: Ediciones El Viso, S.A.

- Martínez-Peñueña, A. (1995). El espacio en las Sintesi de Marinetti. Cuadernos de Filología Italiana, 2, 121-141.

- Pallottino, P. (1991). Storia dell'illustrazione italiana. Bologna: Zanichelli.

- Pérez Samper, M. Á. (2001). Espacios y prácticas de sociabilidad en el siglo XVIII: tertulias, refrescos y cafés de Barcelona. Cuadernos de Historia Moderna, 26, 11-25.

- Poggi, G. (1993). Sui lavori per l'ingrandimento di Firenze (1864-1877). Firenze: Giunti.

- Romby, G. C. (2002). Nello 'stile toscano del Risorgimento': la piazza Cavour di Firenze. En Corsani, G. (coord.). Storia dell'urbanistica. Toscana/VIII. Città, storia, natura: reinvenzione di piazze toscane tra Ottocento e Novecento. Roma: Edizione Kappa, 48-56.

- Rossi, G. (1988). I caffè Letterari in Toscana. Memorie di una civiltà. Lucca: Maria Pacini Fazzi editore.

- Serra, F. (coord.) (2000). Marino Moretti. Aldo Palazzeschi. Carteggio III, 1940-1960. Roma: Edizione di Storia e Letteratura. Università di Firenze.

- Vázquez Astorga, M. (2015). Cafés de Zaragoza. Su biografía, 1797-1939. Zaragoza: Institución Fernando el Católico.

- Vázquez Astorga, M. (2015). Cronaca dei caffè storici di Firenze: 1865-1900. Firenze: Comune di Firenze.

- Vázquez Astorga, M. (2015). La vida social y cultural en los cafés europeos en el último cuarto del siglo XIX. En Chaves Martín, M. Á. (dir.). Comunicación y Ciudad. Madrid: Universidad Complutense de Madrid, 23-37.

- Vázquez Astorga, M. (2018). Il Tivoli di Firenze (Italia): un parco divertimenti ottocentesco. En Biedermann, A., Lázaro Sebastián, F. J. y Sanz Ferreruela, F. (coords.). En los márgenes de la ciudad, del arte y de la crítica. Zaragoza: Prensas de la Universidad de Zaragoza, 75-91.

- Vázquez Astorga, M. (2019). Estampa del Madrid antiguo: el café Suizo (1845-1919). Ars Bilduma, 9, 95-112.

- Ventinove, Z. (1893). Indicatore Generale della città di Firenze. Amministrativo, commerciale, artistico, industriale e stradale. Firenze: Tipografia G. Civelli.

- Ventinove, Z. (1920-1921). Indicatore Generale della città e provincia di Firenze. Guida 
amministrativa, commerciale e professionale. Firenze: Tipografia Carpigiani\&Zipoli Editori.

- Villacorta Baños, F. (2003). Los Ateneos liberales: política, cultura y sociabilidad cultural. Hispania, LXIII/2, 214, 415-442.

- Villacorta Baños, F. (2018). Los Ateneos liberales: política, cultura y sociabilidad cultural. En Guereña, J. L. (ed.). Cultura, ocio, identidades: espacios y formas de la sociabilidad en la España de los siglos XIX y XX. Madrid: Biblioteca Nueva, 45-76.

- Villar, P. (2013). Barcelona, ciudad de cafés (1880-1936). Barcelona: Ajuntament de Barcelona y Ediciones Invisibles.

• Viviani, A. (1964). Giubbe Rosse (1913-1914-1915). Firenze: G. Barbèra.

\section{PRENSA}

- Crónica de Badajoz (18 de julio de 1866). Variedades. La pesca milagrosa, 3-4.

- Diario de Burgos (18 de septiembre de 1956). Bibliografía, 6.

- Diario de Lugo (14 de de octubre de 1882). Folletín del Diario de Lugo. La pesca milagrosa, 3.

- El Bien Público (1 de junio de 1910). Correo de hoy. Desde Barcelona, 2.

- El Cantábrico (14 de octubre de 1896). De todo un poco, 2.

- El Eco de Santiago (13 de febrero de 1905). De aquí y de allá. Los discípulos de Gambrinus, 1.

- El Independiente (16 de mayo de 1908). Gambrinus y Tristán, 3.

- Hoja oficial de la provincia de Barcelona (24 de octubre de 1927). Nuestras dos grandes fábricas de cerveza Moritz, SA y Damm, SA, 13.

- La Cruz (22 de febrero de 1905). Extranjero, 3.

- La Nazione (28 de enero de 1877). Cronaca della città, 4.

- La Nazione (24 de abril de 1882). Cronaca della città, 3.

- La Nazione (15 de junio de 1883). La questione del centro di Firenze, 1-2.

- La Nazione (19 de abril de 1885). Cronaca della città, 2-3.

- La Nazione (24 de abril de 1885). Cronaca della città, 3.

- La Nazione (10 de junio de 1885). Cronaca della città, 3.

- La Nazione (30 de diciembre de 1886). Cronaca della città, 3.

- La Nazione (5 de mayo de 1889). Cronaca della città, 2.

- La Nazione (7 de junio de 1889). Cronaca della città, 3.

- La Nazione (14 de julio de 1889). Cronaca della città, 2.

- La Nazione (23 de marzo de 1890). Cronaca della città, 3.

- La Nazione (17 de septiembre de 1890). Cronaca della città, 2.

- La Nazione (20 de octubre de 1892). Cronaca della città, 3.

- La Nazione (20 de enero de 1893). Per trasloco, 3.

- La Nazione (28 de marzo de 1893). Cronaca della città, 4.

- La Nazione (21 de octubre de 1893). Cronaca della città, 3.

- La Nazione (1 de diciembre de 1894). Cronaca della città, 3.

- La Nazione (24 de marzo de 1895). Cronaca di Firenze, 2.

- La Nazione (17 de noviembre de 1895). Cronaca di Firenze, 3.

- La Nazione (21 de diciembre de 1895). Cronaca di Firenze, 3.

- La Nazione (2 de marzo de 1896). Cronaca di Firenze, 2.

- La Nazione (9 de marzo de 1896). Cronaca di Firenze, 1.

- La Nazione (31 de marzo de 1897). Cronaca di Firenze, 4.

- La Nazione (27 de mayo de 1898). Cronaca di Firenze, 3.

- La Nazione (19 de febrero de 1901). Cinematografo Lumière, 3.

- La Rioja (8 de noviembre de 1901). Sección de Alfaro, 1.

- Las Provincias (15 de marzo de 1931). Tiradas extraordinarias de la Real Sociedad de Tiro de Pichón, 28.

- Macrì, O. (12 de septiembre de 1991). Con Montale alle Giubbe Rosse. La Nazione, 4. 